\title{
As duas faces da moeda: heterotopias e emplazamientos curriculares* $^{*}$

\author{
heterotopies and curricular emplazamientos
} \\ The two faces of the coin:
}

\author{
Alfredo Veiga-Neto** \\ Ao Antonio Flavio Moreira, \\ amigo leal, sagaz e inteligente.
}

\section{Resumo}

A partir dos conceitos foucaultianos de heterotopia e episteme, e do conceito de emplazamiento, proposto por Jorge Larrosa, este artigo discute algumas questões acerca das relações entre o espaço e o currículo. 0 currículo é aqui compreendido como um artefato que contribuiu para um tipo muito particular de representação do espaço, na episteme clássica. 0 currículo funcionou para que a espacialidade medieval - sensorial, finita e fechada - fosse substituída por uma nova espacialidade - abstrata, infinita e aberta. Mais tarde, na Modernidade, tal espacialidade extensional deu lugar a uma espacialidade posicional e reticular, a favor da qual o currículo continuou trabalhando. Agora, na Pós-Modernidade, o espaço está assumindo novas configurações. Para descrever uma dessas novas configurações, é muito útil o conceito foucaultiano de heterotopia. As heterotopias são lugares reais, mas elas parecem estar em oposição em relação aos lugares comuns em que vivemos. Desse modo, as heterotopias confundem a linguagem e perturbam nosso entendimento, mas, ao mesmo tempo, abrem a possibilidade de novos pensamentos, novas representações e novos insights acerca do mundo que nos rodeia. Este artigo sugere que é possível conceber o emplazamiento de Larrosa como uma heterotopia. Nesse caso, dá-se a própria profanação da Pedagogia, de modo que novas possibilidades abrem-se para as nossas teorizações e práticas educacionais.

Palavras-Chave: Currículo; Modernidade; Pós-Moderno; Emplazamiento; Heterotopia; Episteme; Espaço; Pedagogia Profana

\footnotetext{
* Texto preparado por solicitação do Dr. Antonio Flavio Barbosa Moreira (UCP e UERJ), em abril de 2007.

** Doutor em Educação. Professor da Universidade Luterana do Brasil (ULBRA). Professorconvidado no Programa de Pós-Graduação em Educação da Universidade Federal do Rio Grande do Sul - UFRGS (Canoas/Brasil). alfredoveiganeto@uol.com.br.
} 


\section{Abstract}

From the foucaultian concepts of heterotopy and episteme, and from the concept of emplazamiento developed by Jorge Larrosa, this paper discusses some questions about the relations between the space and the curriculum. Here, the curriculum is assumed as an school artifact implicated with a very particular kind of representation of the space, in the classic episteme. It is argued that the curriculum contributed to the substitution of the medieval spaciality - sensorial, finite and closed - for a new one - abstract, infinite and open. Later, in Modernity, such extensional spaciality was replaced by a positional and reticular or gridded spaciality, for which the curriculum still proceeded. And now, in Postmodernity, the space is assuming new configurations. To describe one of these configurations, is very useful the foucaultian concept of heterotopy. The heterotopies are real places; but they seem to be in opposition with relation to the common places where we live. So, the heterotopies confuse the language and disturb our understanding; but, at the same time, they open the possibility of new thoughts, new representations and new insights about our world. This paper suggests that it is possible conceive the larrosian emplazamiento as an heterotopy. In this case, it happens a very profanation of the Pedagogy, so that new possibilities are open to our educational theories and practices.

Keywords: Curriculum; Modernity; Postmodernity; Emplazamiento; Heterotopy; Episteme; Space; Profane Pedagogy

A época atual seria, talvez acima de tudo, a época do espaço.

(Foucault, 2001, p. 1571)

Em outras ocasiões já recorri a essa conhecida frase que de novo me serve de epígrafe. O famoso texto em que ela foi escrita - a conferência que Michel Foucault proferiu para um grupo de arquitetos franceses, em 1967, sob o título de "Outros espaços" - tem sido muito útil para compreendermos o caráter espacial (tanto espacializado quanto espacializador) do mundo moderno. Aquele texto, combinado com importantes insights de vários outros autores, ${ }^{1}$ me tem sido útil também para discutir o papel que a educação escolarizada desempenhou e certamente continua desempenhando na percepção do espaço e do tempo e nos usos que se vem fazendo deles, ao longo da Modernidade. Em suma, nos últimos anos venho insistindo nas íntimas articulações entre a escola e o mundo moderno, tomando o espaço e o tempo como operadores da maior importância para tais articulações. ${ }^{2}$

1 Mesmo sob o risco de ser parcial, refiro-me aqui principalmente a David Harvey, Paul Virilio, Gilles Deleuze, Gilles Lipovetsky, Gianni Vattimo, Jean-François Lyotard, Zygmunt Bauman.

2 Também com o objetivo de prestar algum serviço àqueles que se interessam por esses assuntos, não há como deixar de referir minhas contribuições nesse campo: Veiga-Neto (1996, 2000a, 2000b, 2002a, 2002b, 2003, 2005, 2006), Lopes e Veiga-Neto (2004) e VeigaNeto e Lopes (2007). 
Agora, volto mais uma vez a essas questões. Minha atenção continua focada nas relações entre a educação escolarizada - e, em especial, o currículo -, o espaço e o tempo. Mas aqui me ocuparei mais em colocar em pauta o elemento espaço, a partir dos conceitos foucaultianos de episteme e, principalmente, de heterotopia, conforme o filósofo (brevemente) o desenvolveu na conferência de 1967. Recorrerei, também, ao conceito de emplazamiento desenvolvido por Jorge Larrosa (1998). Isso significa, então, que aqui darei prioridade ao espaço. É claro que em vários momentos aparecerão questões relativas também ao tempo, dada a impossibilidade de pensá-los em separados; afinal, tempo e espaço parecem manter entre si relações inextricáveis, conectando-se um ao outro no movimento e na grandeza que lhe serve de medida, a velocidade. Assim como o tempo desenrola-se no espaço, para nós não faz sentido pensar um espaço fora do tempo. Nas palavras de Foucault (2001, p. 1.572), “o próprio espaço tem, na experiência ocidental, uma história; não é possível desconhecer esse entrecruzamento fatal do tempo com o espaço".

Resumindo, além de me valer do pensamento de Foucault, pretendo explorar um pouco mais as relações entre o currículo e o espaço, de modo a articular tais relações com as sugestões de Jorge Larrosa a favor de uma Pedagogia Profana. Assim, este texto tem um caráter pouco mais do que exploratório, movimentando-se num tempo em que a Modernidade já se transmutou, num tempo que alguns estão chamando de Modernidade Tardia, enquanto que outros chamam de Modernidade Líquida (Bauman, 2001, 2004, 2007). Continuo preferindo a palavra pós-moderno para designar todo o conjunto de práticas e representações que vivemos no mundo de hoje. ${ }^{3}$

E já que estamos falando de espaço, pode-se pensar que para este texto vale a metáfora da moeda.

Numa das faces da moeda, desenvolvo alguns conceitos foucaultianos para pensar o currículo, principalmente em suas relações com o espaço, e para sugerir que hoje ele pode ser compreendido como uma heterotopia. Assim, chamarei a primeira seção de "A face heterotópica".

3 Não há, certamente, como entrar aqui em detalhes sobre o pós-moderno. Os interessados encontrarão farto e instigante material em Bauman (2001, 2004, 2007) e em Harvey (1996). 
$\mathrm{Na}$ outra face da moeda, discuto as contribuições de Larrosa em prol de uma dessacralização da Pedagogia contemporânea. Aí me parece particularmente interessante o seu conceito de emplazamiento, presente no livro Pedagogia profana: danças, piruetas e mascaradas (Larrosa, 1998). Chamarei a segunda seção de "A face profana".

Se a metáfora da moeda vale como referência para este texto, vale também para pensarmos o currículo. Ele pode ser entendido como dando corpo a essa moeda, como constituindo-a em sua materialidade e espessura. Vamos logo então à moeda, ao mesmo tempo que discutiremos a invenção do currículo, esse artefato cujo papel foi decisivo tanto na afirmação de um novo tipo de espacialização quanto na disseminação de novas maneiras de perceber o espaço e de dar sentidos a ele. Em outras palavras, a história do currículo é indissociável das epistemes com as quais ele mantém conexões indissociáveis. Isso significa, então, que temos de começar atacando a questão a partir do conceito de episteme.

\section{A face heterotópica}

Um dos conceitos mais interessantes, abstratos e (talvez) difíceis de que Michel Foucault lançou mão foi o de episteme. De modo um tanto aproximativo, podemos dizer que, para o filósofo, episteme designa todo um conjunto de modos de pensar e de conhecer que, "numa cultura e num momento dado, [...] define as condições de possibilidade de todo o saber" (Foucault, 1966, p. 179). A episteme reúne "o conjunto de relações que se pode descobrir, numa época dada, entre as ciências quando essas são analisadas no nível de suas regularidades discursivas" (Castro, 2004, p. 112).

Os primeiros usos que Foucault fez de episteme ocorrem no Prefácio de As palavras e as coisas (Foucault, 1966), a fim de caracterizar a Época Clássica como o domínio da ordem e da representação. A questão que se colocava era, justamente, contrastar a Época Clássica com a Idade Média - que lhe antecedeu imediatamente - e com a Modernidade que logo lhe sucederia.

Uma das condições de possibilidade para que a episteme da ordem e da representação se estabelecesse, na passagem da Idade Média para a Época Clássica, foi, certamente, toda uma nova forma de perceber o espaço e o tempo e os novos sentidos que lhe foram sendo atribuídos. 
Tenho insistido que, ao invés de pensarmos em relações de causa e efeito nesses casos - entre, de um lado, a ordem e a representação e, de outro lado, essas novas percepções e sentidos espaciais e temporais -, é preciso compreender que se trata, aqui, de relações de imanência, de modo que todos esses elementos se implicam mutuamente e mantêm influências recíprocas. Assim, na medida em que a ordem e a representação se dão em tempos e espaços finitos, ambas só podem ser pensadas dentro - ou sobre, ou a partir - de um fundo que é necessariamente temporal e espacial. Por sua vez, tal fundo espacial e temporal "precisa" de todo um conjunto de percepções e representações ${ }^{4}$ que lhe dêem sentido.

Ainda que tudo isso às vezes nos pareça autodemonstrado e evidente por si mesmo, é preciso ser mais sutil e ir mais longe na História, de modo que se possa compreender o caráter construído de tais entendimentos, percepções, representações etc. É preciso recuar um pouco e examinar como o mundo medieval entendia, vivia e significava o tempo e o espaço. Vários estudos têm mostrado que, ao longo da Idade Média, os europeus, sintonizados com o paradigma aristotélico e mergulhados nos valores e nas práticas cristãs, entendiam o espaço como o outro das coisas e o tempo como uma função dependente do espaço, assumindo o movimento como o elemento articulador entre ambos. A cosmologia medieval entendia o espaço como finito e cindido em dois: um espaço interno, sub-lunar, rígido, sensorial, percorrível, imediato e familiar; um espaço externo, misterioso, mágico, distante e inacessível. O tempo, por sua vez, era entendido como finito; assim, por exemplo, vivido no seu imediatismo, o tempo, para Santo Agostinho, não passava de um indefinível estado de espera, cujo desenlace acabaria se dando no fim dos tempos, no Juízo Final.

Foucault (2001, p. 1.571) diz que o espaço, na Idade Média era "um conjunto hierarquizado de lugares [...] onde as coisas encontravam sua localização e seu repouso naturais". Desse modo, o espaço medieval era

4 Estou usando a palavra "representação" no sentido de atribuição de significado. Além disso, aqui sigo o Segundo Wittgenstein, para quem "as palavras possuem significados (Bedeutung), mas por si só não fazem sentido (Sinn); por outro lado, as proposições, os enunciados, não possuem significado, mas fazem sentido na medida que representam um estado de coisas ou uma situação possível" (Veiga-Neto; Lopes, 2007, p. 10). Para Glock (1998, p. 332), o significado não é nem falso nem verdadeiro; mas os sentidos, sim, pois se estabelecem por "uma combinação de objetos que pode ou não se dar, conforme a proposição seja verdadeira ou falsa. A proposição mostra seu sentido". Como argumentou Condé (2004, p. 51), para o Segundo Wittgenstein o significado de uma palavra é determinado pelo uso que dela se faz; desse modo, "o uso é condição suficiente para a significação". 
um espaço de localização. É fácil ver que tal entendimento medieval sobre o espaço não poderia abrigar a ordem e a representação; seria preciso uma verdadeira revolução paradigmática para que se estabelecesse uma nova lógica de ordenamento das coisas do mundo e para que a representação assumisse o estatuto que passou a assumir logo após o Renascimento. Mas talvez ainda mais importante do que isso: seria preciso uma revolução para que ambas, ordem e representação, se firmassem com toda a primazia com que se firmaram, isto é, para que ambas passassem a funcionar como fundo de inteligibilidade e, assim, "comandassem" toda a lógica do entendimento, a partir dos Seiscentos.

O heliocentrismo copernicano é tomado como o ponto de inflexão dessa verdadeira revolução paradigmática, no sentido dado por Kuhn (1979) a essa expressão. De fato, ainda que alguns, já um pouco antes do Renascimento, tenham preparado o terreno para a virada de Copérnico, se estivermos interessado em registrar autorias é a esse que se pode atribuir a ruptura com a espacialidade e a temporalidade medievais - uma ruptura para a qual até mesmo a expansão das navegações certamente estavam contribuindo de modo decisivo. Mas foi com Galileu que aquele entendimento medieval entrou ampla e definitivamente em crise; a partir dele, o espaço passou a ser entendido como uma extensão, em que "o lugar de uma coisa não era mais do que um ponto em seu movimento" (Foucault, 2001, p. 1.572).

Não se trata, aqui, de entrar em detalhes nem sobre as lutas que se travaram nesse campo, ao longo dos séculos XVI e XVII, nem sobre os muitos fatores e personagens envolvidos com elas. O que importa é, sim, compreender que, na segunda metade do século XVII, já estando dadas todas as condições de possibilidade para o completo abandono do paradigma do espaço e do tempo medievais, Isaac Newton assumiu o espaço e o tempo como invariantes e transcendentes, isso é, descolados - ou, talvez melhor, não dependentes - de toda e qualquer experiência humana.

De uma maneira um tanto simplificada, pode-se dizer que Newton não estava propriamente descobrindo a verdadeira e definitiva natureza do espaço e do tempo. Ao contrário, o que ele estava fazendo era inventando um determinado e bem particular entendimento acerca de ambos. Tratavase de um entendimento que acabaria presidindo toda a Física ao longo dos dois séculos seguintes e que só entraria em crise no início do século XX, com a Teoria da Relatividade. É claro que Newton não esteve sozinho 
nesse processo de transcendentalização do espaço e do tempo; mas se pode atribuir a ele a tematização pormenorizada e, enfim, a fixação dessas - e, nesse âmbito, de muitas outras - invenções. Enfim, a invariância e a transcendentalização do espaço e do tempo implicavam fazer do espaço e do tempo duas "entidades" distintas, independentes uma da outra.

Aqui já cabe uma pergunta: que têm a ver o espaço, o tempo e o conceito foucaultiano de episteme com o currículo? Que tudo isso está fazendo aqui, no meio de um conjunto de textos de Estudos de Currículo? ${ }^{5}$ Que interesse têm tais considerações acerca da passagem da Idade Média para a Época Clássica? As respostas a essas perguntas são relativamente simples: como reiteradas vezes tenho argumentado, o currículo pode ser compreendido como o mais poderoso artefato pedagógico que operou no sentido de fixar e disseminar as novas espacialidades e temporalidades, a partir do final do Renascimento.

Mas, para compreender o papel do currículo nas mudanças com as quais ele se articula e, até mesmo, para as quais ele veio prestar grande serviço, é preciso levar em consideração a sua ampla, rápida e firme disseminação: inventado no âmbito das Universidades, o currículo rapidamente passou a ser "usado" nos mais diferentes tipos de escolas e colégios.

Inventado na passagem do século XVI para o século XVII, o currículo não apenas ordenou cada vez mais fortemente o funcionamento das universidades e dos colégios como também "trouxe um sentido maior de controle tanto ao ensino quanto à aprendizagem" (Hamilton, 1992, p. 43) nessas instituições. Se, por um lado, isso se apresentou como uma notável novidade para a prática e a teorização pedagógicas, por outro lado, diferentemente do que ocorrera até então com a escolástica medieval, abria-se a possibilidade de trazer, para as escolas, todo um novo conjunto de saberes mais ligados à prática da vida. Soma-se, a tudo isso, o próprio caráter espacial do currículo, visível até mesmo na palavra: curriculum como a corrida a ser realizada ao longo de um determinado (per) cursus/percurso. Por outro lado, a arquitetura que logo de início foi atribuída ao currículo -

5 Muitos autores vêm usando a expressão Estudos de Currículo - ou, segundo outros, Curricologia - para designar o campo de saberes pedagógicos que se ocupa com o currículo, segundo uma variada gama de tendências epistemológicas e ideológicas, que vão desde uma perspectiva mais centrada no tecnicismo instrumental, até as tendências pósestruturalistas e pós-modernas, passando pelas importantes e numerosas contribuições da Teoria Crítica. 
a saber, uma arquitetura que se centrava na disposição disciplinar das representações que constituíam o conjunto todo - funcionou como mais um elemento na espacialização dos próprios saberes curricularizados.

O caráter espacial e temporal do currículo atendia e afirmava as novas configurações para o espaço, que se engendravam entre a segunda metade do século XV e a primeira metade do século XVI. O rompimento com o universo medieval, fechado e finito, implicou o abandono da estrutura monótona e estável das distribuições e disposições lineares que haviam funcionado na Idade Média: o Trivium e o Quadrivium. O currículo, com sua estrutura disciplinar, "abriu o pensamento humano ao infinito, tanto horizontal quanto verticalmente" (Veiga-Neto, 2002a). Como expliquei em outro lugar, tal abertura deu-se tanto "horizontalmente, em novos campos de conhecimento, quanto verticalmente, em cada vez menores subdivisões numa dada linha hierárquica que vai do mais geral para o cada vez mais particular" (Veiga-Neto, 1996, p. 228). A essas duas dimensões - ou talvez seja melhor dizer: a esses dois eixos - acrescentaramse ainda mais duas dimensões ou eixos: o conteúdo e o tempo. O conteúdo conferiu volume ao currículo, um artefato que então se tornou elástico e capaz de alojar a representação. O tempo jogou o currículo na possibilidade do acontecimento, na sucessão da história.

Assim, o currículo ao mesmo tempo em que instituía uma nova ordem para as coisas (deste mundo) colocava-se como um artefato, ele mesmo, aberto para este mundo, um mundo que passava a ser entendido como aberto e infinito. E tal abertura só poderia ser realizada se entrasse em jogo o tempo, ou seja, se fosse possível - como, de fato, passou a ser - que se agregassem ao artefato novas representações conforme o desenrolar dos acontecimentos.

Indo mais adiante na história de rupturas e descontinuidades espaçotemporais, Foucault nos diz que, depois da ênfase na extensão, característica da Época Clássica, o espaço passou a ser entendido, já na Modernidade, como posicionamento. Atualmente, então, o lugar que cada corpo ocupa no espaço faz sentido não por si mesmo, mas em função das suas relações com os lugares vizinhos. A posição relativa é o que mais importa: "estamos numa época em que o espaço se oferece a nós sob a forma de relações de posicionamentos" (Foucault, 2001, p. 1.573), uma estrutura que guarda forte correspondência com a grade. Chamei de "lugarização" a essa capacidade diferencial de criar lugares no espaço ou de trocar as posições relativas de modo mais ou menos controlado, com o 
fim de maximizar as vantagens por ocupar essa ou aquela posição. $O$ currículo parece se tornar, então, agora mais importante do que nunca, uma vez que - ao ser pensado e praticado de modo flexível, cambiante e adaptável - ele já estará ensinando modos de pensar e agir também flexíveis, cambiantes e adaptáveis (Veiga-Neto, 2005).

É nesse ponto que se pode pensar no conceito de heterotopia. Esse conceito foi proposto por Foucault para designar todo e qualquer lugar cuja existência - em contraposição às utopias - é real e que, embora localizáveis, parecem se encontrar por fora de todos os lugares comuns em que vivemos. As heterotopias são lugares que parecem manter uma relação de neutralização, suspensão ou inversão com os demais lugares de nossos cotidianos. Elas nos inquietam, pois aparecem como que deslocadas e desencaixadas em relação aos demais lugares que habitamos. Elas nos aparecem como lugares fora de quaisquer outros lugares (Martins, 2002). É daí que vem a sensação de que as heterotopias atrapalham a linguagem, alteram os sentidos e perturbam as relações aparentemente estáveis entre as palavras e as coisas (Foucault, 1966).

Naquela conferência proferida aos arquitetos, o filósofo recorre ao espelho como exemplo de uma utopia - pois aquele que ali se vê na realidade não existe de fato - e, ao mesmo tempo, de uma heterotopia pois, afinal, o espelho existe de fato... Os cemitérios, as casas de repouso, as clínicas psiquiátricas, os jardins, os museus, as bibliotecas, os bordéis, as colônias jesuíticas dos séculos XVII e XVIII e os navios são os lugares que Foucault toma como exemplos de heterotopias e sobre os quais desenvolve breves comentários. ${ }^{6}$

Pode-se pensar que a demora em autorizar a publicação de "Outros espaços" tenha decorrido do desinteresse de Foucault pelo assunto ou até mesmo de sua insegurança em colocar em circulação a heterotopologia que sugeria na conferência de 1967. Afinal, ainda que aquele texto seja bastante provocativo e demonstre uma aguda sensibilidade do filósofo para com as novas espacialidades então nascentes, é evidente o caráter provisório e quase experimental que ele imprime ao texto. Se isso é, de certa forma, lamentável, não há dúvida de que se pode aproveitar a provocação e a provisoriedade para levar adiante o caminho aberto por Foucault. Seja como for, trata-se de um conceito ainda à espera de maior

$6 \quad$ Foi talvez por se dar conta de que havia desenvolvido muito pouco o conceito de heterotopia que Foucault não autorizou, durante quase vinte anos, a publicação dessa conferência. 
desenvolvimento. Na próxima seção, ao examinar a segunda face da moeda, voltarei a essa questão.

\section{A face profana}

No conhecido texto "Sobre a lição: ou do ensinar e do aprender na amizade e na liberdade", 7 Jorge Larrosa propõe "a experiência da leitura em comum como um jogo dos possíveis do ensinar e do aprender". O filósofo espanhol procura estabelecer o que tem a ver o jogo do ensinar e do aprender "com a experiência da liberdade, com essa curiosa relação de alguém consigo mesmo, à qual chamamos de liberdade, e com a experiência da amizade, com essa curiosa forma de comunhão com os outros que chamamos de amizade" (Larrosa, 1998, p. 174). Para ele, promover uma pedagogia dessacralizada implica promover uma experiência aberta: não se tem previamente nem um caminho traçado de todo nem mesmo a garantia do "atingimento" de um "final feliz". Isso nada tem a ver com falta de planejamento. Também nada tem a ver com aquele estado de coisas que, num empréstimo espúrio tomado de outro campo de saberes, alguns chamam de "princípio da incerteza" ou "princípio da indeterminação". Também não se trata de um "tudo vale". A abertura da experiência aponta para o caráter radicalmente contingente da experiência humana e para o deslocamento do foco pedagógico: da ênfase no controle estrito dos objetivos para a ênfase no próprio acontecimento pedagógico. ${ }^{8}$ Sobre isso, uma passagem é especialmente interessante: "O que se deve ler na lição não é o que o texto diz, mas aquilo que ele dá o que dizer. [...] Ler não é apropriar-se do dito, mas recolher-se na intimidade daquilo que dá o que dizer ao dito." (Larrosa, 1998, p. 177)

Entendendo a lição - ou, se quisermos, a aula - como o lugar no espaço em que se realiza ou materializa o convite-convocação que o professor lançou ou dirigiu aos alunos para que viessem partilhar publicamente da experiência da leitura em comum, Larrosa diz que "o texto converte-se em palavra emplazada, em palavra colocada na plaz̧a, no lugar público, no lugar que ocupa o centro para simbolizar o que é de

7 Trata-se do Capítulo 6 do livro Pedagogia profana: danças, piruetas e mascaradas (Larrosa, 1998).

8 Não há como deixar de notar, aqui, uma certa dose de spinozismo, talvez um tanto em sintonia com o princípio taoísta do wu-wei - algo como "deixar-estar", de modo que o acontecimento se cumpra por si mesmo. 
todos e não é de ninguém, o que é comum". A palavra é emplaz̧ada quando "o texto é algo que se pode realmente chamar de comum"; do mesmo modo, aqueles que assistem à lição tornam-se "emplazados pelo comum do texto" (Larrosa, 1998, p. 178), o único elemento capaz de manter uma amizade ou philía numa comunidade de diferentes.

Vê-se aí todo um refinado jogo de palavras, cuja beleza advém não apenas do ritmo e da sonoridade conseguida pelo autor, mas, sobretudo, da profundidade das próprias idéias que encerra. É preciso pensar em todas essas palavras tomando-as nos sentidos mais amplos que for possível tomá-las. Assim, como o próprio Larrosa (1998, p. 174) adverte, "uma lição é uma leitura e ao mesmo tempo uma convocação à leitura, uma chamada à leitura". Igualmente, quanta aproximação se pode fazer entre ler, lição, eleger, leitura...; entre convidar, envidar, convocar, voz...; entre emplazar, plaza, emplazamiento, praça... É preciso, também, notar que boa parte de todo esse jogo de palavras perdeu-se na tradução do espanhol para o português, pois não temos uma palavra que permita as sutilezas dos deslizamentos sonoros e de sentido entre plaza, emplazar e emplazamiento. Palavras tais como localização, local e praça não se prestam para o jogo pretendido pelo autor. Por isso, talvez seja melhor mantermos plaza e suas derivadas em sua forma original...

É o emplazamiento - do texto e daqueles que participam da lição que garante a manutenção da heterogeneidade sem que essa descambe para a pura e simples dispersão, para o desgaste da entropia, para a corrupção. É o emplazamiento que garante, ao mesmo tempo, o caráter público e aberto do espaço onde se dá o ensinar e o aprender e o "em comum" de uma atividade partilhada entre diferentes; o emplazamiento garante, ao mesmo tempo, a dispersão e a canalização da ação pedagógica, sem que haja aí qualquer antinomia.

Uma pedagogia sagrada procuraria logo resolver essa aparente contradição, buscando reduzir a diferença à unidade e submeter o diverso a uma suposta síntese. Precisaria lembrarmos os pedagogos dialéticos, sempre de plantão, sempre prontos para a tarefa de varrer do mundo aquilo que pensam estar atravancando o (assim chamado) "curso natural da história"? A proposta profana de Larrosa é bem outra: entendendo que uma comunidade deve ser entendida como o lugar ocupado por aqueles "que não têm em comum senão o espaço que faz possível suas diferenças", ele diz que "a comunidade dos convocados à lição têm seu ser na dispersão e na descontinuidade, na divergência e na dessemelhança, na distinção e 
no disssenso" (Larrosa, 1998, p. 180). Não se trata de buscar a homogeneidade dos saberes, mas sim a heterogeneidade do aprender, única maneira de darmos espaço à diferença e garantirmos a manutenção da alteridade.

Por isso, os participantes de uma experiência pedagógica profana não estão em comunhão ou conjugação; ainda que ressoem juntos, eles não estão naquela situação que se costuma chamar de "em comum". Eles mantêm entre si não mais do que uma "relação refratária à síntese, alérgica à totalização, resistente à generalização" (Larrosa, 1998, p. 180). Nesse caso, a philía não consiste em olhar um para o outro, mas em olharem todos na mesma direção, sem que isso signifique apagar ou contornar as diferenças que existem entre todos.

Assim, se por um lado o emplazamiento significa a instauração de um lugar comum a todos e no centro de um espaço qualquer, por outro lado é nesse lugar que se abriga a diferença, é nele que se pode pensar o até então impensado, é dele que pode sair algo de novo. A plaza pode ser entendida, então, como uma heterotopia, como um lugar que é real mas que se encontra fora de - e como que invertido em relação a - todo e qualquer outro lugar real que conhecemos e com os quais mantemos nossas relações cotidianas. $\mathrm{Na}$ plaz̧a, nossas relações serão diferentes, especiais. $\mathrm{E}$ tais relações são diferentes e especiais não apenas em relação à plaz̧a, mas, também, em relação a todos aqueles que dão vida à plaza: os alunos.

A operação de emplazamiento pode ser entendida, desse modo, como uma lugarização heterotópica, isto é, como a transformação de um espaço qualquer, até então vazio, em uma porção de espaço agora carregada de sentidos: uma plaza. Cabe ao professor a promoção e a condução dessa transformação. Nas palavras de Larrosa (1998, p. 174), “o professor aquele que dá o texto a ler, aquele que dá o texto como um dom, nesse gesto de abrir o livro e de convocar à leitura - é o que remete o texto. $\mathrm{O}$ professor seleciona um texto para a lição e, ao abri-lo, o remete. Como um presente, como uma carta". O sentido da plaz̧a, isto é, o sentido que será conferido à plaza advirá do sentido que o professor conseguir imprimir à sua carta, ao seu presente:

Uma vez que só se presenteia o que se ama, o professor gostaria que seu amor fosse também amado por aqueles aos quais ele o remete. E uma vez que uma carta é como uma parte de nós mesmos que remetemos aos que amamos, esperando resposta, o professor gostaria que essa parte de si mesmo, que dá a ler, também despertasse 
o amor dos que a receberão e suscitasse suas respostas. (Larrosa, 1998, p. 174-175).

Dessa maneira, o papel do professor é absolutamente fundamental. Fundamental não só porque importante, mas também porque é ele que dá os fundamentos do processo. Desse primeiro passo fundante - a saber: a escolha do texto e a sua remessa aos alunos - dependerão os passos seguintes. É a partir desse fundamento que o processo poderá se encaminhar ou se desencaminhar. No fundo, então, o (des)caminho dependerá do amor do professor pelo texto...

No sentido pedagógico, o emplazamiento implica a combinação entre a necessidade de existir um texto - aqui entendido como qualquer coisa a ser ensinada e aprendida - e a contingência do acontecimento que põe o texto a funcionar. Numa pedagogia assim profana(da), o controle do professor sobre a ação do ensinar concentra-se na seleção do texto, no convite-convocação que faz aos alunos e nos cuidados para que o emplazamiento aconteça. Daí para diante, tudo é lucro...

Emplazada, a palavra-texto é parte do currículo; ela faz as vezes daquilo que se convencionou chamar de conteúdo; assim, a palavra-texto emplazada recheia a grade e dá volume ao conjunto. Mas será no acontecimento que ela, colocando-se em movimento, atualizará a sua função. Como vimos, é aí que ela corre o risco de se perder; é aí, então, que o processo precisa de novo do professor. Se na escolha do presente a ser enviado o papel do professor era absolutamente fundamental, no desenrolar do presente ele continua sendo crucial. É crucial não só porque importante, mas também porque é ele que pode orientar os caminhos possíveis nos cruzamentos e desvios que vão surgindo com o desenrolar dos acontecimentos. Mas essa orientação não deve jamais ser confundida com controle!

A simetria entre, de um lado, o movimento da palavra-texto emplazada e, de outro lado, o caráter líquido do pós-moderno é mais do que evidente. Flexibilidade, interdisciplinaridade, contextualização, adaptação, transversalidade - todas elas palavras tão em voga na teorização e nas práticas curriculares contemporâneas - parecem sintonizadas com o currículo emplazado. Mas se aí existe simetria e sintonia, não se deve pensar que basta flexibilizar, contextualizar, transversalizar ou adaptar o currículo para que se profane a pedagogia. Não basta estar no pós-moderno para que a pedagogia se dessacralize; nada existe aí de automático... Talvez o risco maior seja, até mesmo, de que - em nome da flexibilização, da 
contextualização, da adaptação, da transversalização - leve-se a prática curricular a um enrijecimento e a um controle que nada tem a ver com uma Pedagogia Profana.

Pode-se pensar na sintonia da Pedagogia Profana com o pósmoderno, mas não com a sociedade de controle - no sentido que Foucault e Deleuze deram a essa expressão. É bom insistir: a profanação da Pedagogia é uma tentativa de nos opormos à sociedade de controle! E mais: criar heterotopias e emplazar o texto são operações que vão na contramão do controle social.

O quanto de heterotopização e o quanto de emplaz̧amiento serão conseguidos dependerá do quanto quisermos, pudermos e conseguirmos seguir as sugestões de Foucault e de Larrosa. Criar novas heterotopias, promover novos emplazamientos são desafios que se colocam à frente de todos aqueles interessados em não se deixarem levar pelos controles do pós-moderno. Para aqueles que nos pedem novas e urgentes alternativas práticas no campo dos Estudos de Currículo, podemos lembrar que recém foram dados os primeiros passos nessas propostas pedagógicas profanas. Aqueles que têm pressa não devem esquecer que foi preciso muito tempo para que a Pedagogia Moderna, de cujas raízes sagradas cresceram tantas árvores frondosas, desse os frutos importantes que, de fato, conseguiu dar. Agora, novas demandas e novas dificuldades colocam-se diante de nós. Trata-se de demandas e dificuldades para as quais a teorização e as práticas pedagógicas tradicionais parecem não dar conta, parecem ter pouco a dizer. Por outro lado, novas possibilidades abrem-se diante de nós; além de tudo o que foi discutido neste texto, há muitos outros conceitos, outros autores e outras frentes se abrindo. Num pós-moderno no qual não há mais lugar para as metanarrativas que alimentaram a Pedagogia Sagrada, certamente vale a pena investir nessas novas possibilidades. São possibilidades talvez ainda modestas, certamente não-salvacionistas, bastante esparsas e que não prometem muito; mas são o que temos.

\section{Referências Bibliográficas}

BAUMAN, Zygmunt. Modernidade líquida. Rio de Janeiro: Jorge Zahar, 2001. BAUMAN, Zygmunt. Amor líquido: sobre a fragilidade dos laços humanos. Rio de Janeiro: Jorge Zahar, 2004.

BAUMAN, Zygmunt. Vida líquida. Rio de Janeiro: Jorge Zahar, 2007. 
CASTRO, Edgardo. El vocabulario de Michel Foucault: un recorrido alfabético por sus temas, conceptos y autores. Buenos Aires: Prometeo, 2004.

CONDÉ, Mauro Lúcio. As teias da razão: Wittgenstein e a crise da racionalidade moderna. Belo Horizonte: Argvmentvm, 2004.

FOUCAULT, Michel. Les mots et les choses: une archéologie des sciences humaines. Paris: Gallimard, 1966.

FOUCAULT, Michel. Des espaces autres. In: FOUCAULT, Michel. Dits et écrits II: 1976-1988. Paris: Quarto, Gallimard, 2001. p. 1.571-1.581.

GLOCK, Hans-Johann. Dicionário Wittgenstein. Rio de Janeiro: Jorge Zahar, 1998. HAMILTON, D. Sobre as origens dos termos classe e curriculum. Teoria \& Educaşão. Porto Alegre, n. 6, p. 33-52, 1992.

HARVEY, David. A condição pós-moderna. São Paulo: Loyola, 1996.

KUHN, Thomas. A estrutura das revoluções cientificas. São Paulo: Perspectiva, 1978.

LARROSA, Jorge. Pedagogia profana: danças, piruetas e mascaradas. Porto Alegre: Contrabando, 1998.

LOPES, Maura Corcini; VEIGA-NETO, Alfredo. Os meninos. Educação \& Realidade, Porto Alegre, UFRGS, v. 29, n. 1, p. 229-239, 2004.

MARTINS, Carlos José. Utopias e heterotopias na obra de Michel Foucault: pensar diferentemente o tempo, o espaço e a história. In: RAGO, Margareth; ORLANDI, Luiz B.; VEIGA-NETO, Alfredo (Org.). Imagens de Foucault \& Deleuze: ressonâncias nietzschianas. Rio de Janeiro: DP\&A, 2002. p. 84-98.

VEIGA-NETO, Alfredo. A ordem das disciplinas. Tese (Doutorado em Educação) - Faculdade de Educação, Universidade Federal do Rio Grande do Sul, Porto Alegre, 1996.

VEIGA-NETO, Alfredo. Espaços, tempos e disciplinas: as crianças ainda devem ir à escola? In: ALVES-MAZZOTTI, Alda et al. Linguagens, espacos e tempos no ensinar e aprender. Rio de Janeiro: DP\&A, 2000a. p. 9-20.

VEIGA-NETO, Alfredo. Espacios que producen. In: GVIRTZ, Silvina (Org.). Textos para repensar el día a día escolar. sobre cuerpos, vestuarios, espacios, lenguajes, ritos y modos de convivencia en nuestra escuela. Buenos Aires: Santillana, 2000b. p. 195-212.

VEIGA-NETO, Alfredo. Espaço e currículo. In: LOPES, Alice C.; MACEDO, Elizabeth F. (Org.). Disciplinas e integraşão curricular. história e políticas. Rio de Janeiro: DP\&A, 2002a. p. 201-220.

VEIGA-NETO, Alfredo. De geometrias, currículo e diferenças. Educação e Sociedade, Campinas, v. XXIII, n. 79, p. 163-186, 2002b.

VEIGA-NETO, Alfredo. Pensar a escola como uma instituição que pelo menos garanta a manutenção das conquistas fundamentais da Modernidade. In: COSTA, Marisa V. (Org.). A escola tem futuro? Rio de Janeiro: DP\&A, 2003. p. 103-126. 
VEIGA-NETO, Alfredo. Princípios norteadores para um novo paradigma curricular: interdisciplinaridade, contextualização e flexibilidade em tempos de Império. In: VEIGA, Ilma P. A.; NAVES, Marisa Lomônaco. Currículo e avaliação na Educação Superior. Araraquara: Junqueira \& Marin, 2005. p. 25-51.

VEIGA-NETO, Alfredo. Memória, tempo, cotidianos. In: GARCIA, Regina L.; ZACCUR, Edwiges (Org.). Cotidiano e diferentes saberes. Rio de Janeiro: DP\&A, 2006. p. 111-124.

VEIGA-NETO, Alfredo; LOPES, Maura Corcini. Identidade, cultura e semelhança de família: as contribuições da virada lingüística. In: BIZARRO, Rosa (Org.). O en e o outro. Porto: Ed. da Universidade do Porto, 2007. (No prelo).

Recebido em: 30/03/07 Aprovado em: 26/04/07 